\title{
ANALYSIS ON PROCESS QUALITY CONTROL TECHNOLOGY OF GEOGRAPHICAL NATIONAL CONDITIONS MONITORING
}

\author{
Su Yin*, Haitao Zhao, Chunxi Chen, Bingquan Yao, Jin Zhou \\ National Quality Inspection and Testing Center for Surveying and Mapping Products, 28 West Lianhuachi Road, Beijing, China
}

\author{
Commission III, WG III/IVb
}

KEY WORDS: Process Quality Control, Quality Control Key Points, Quality Control Inspection, Geographic National Conditions Monitoring, Process Quality Analysis.

\begin{abstract}
:
The process quality inspection of geographic national conditions monitoring is an important means of quality control, and it is essential to improve the effectiveness of its role. Starting from the influencing factors and inspection methods of process quality control, the key points are designed and the content of process quality control is proposed. Based on this, combined with the practical application in the 2016-2020 geographic national conditions monitoring project, the problems existing in the geographic national conditions monitoring process are summarized and analysed.
\end{abstract}

\section{INTRODUCTION}

Geographic national conditions monitoring (hereinafter referred to as "monitoring") is based on the results database formed by the national geographic conditions census, adopting a consistent content system, targeting the whole country, oriented to common goals, and comprehensively considering multiple needs. The monitoring data covers the entire area of the country, and the collection involves three-level classification and more than one hundred indicators. Carrying out the process quality inspection of the monitoring is an important means of quality control (Li, Ma, Shao, 2018).

Monitoring data production consists of a series of processes. The activities of the quality inspection involved in the process is achieved by setting up key quality gates in important processes such as quality management, orthophoto processing, in-house editing, and field verification. By ensuring the technical process, collection indicators, processing methods and other important indicators meet technical design requirements, it is effectively eliminating technical deviations in data output and correcting common errors in process results (Li, Sui, Shan, 2012).

According to the production characteristics of the monitoring data, this paper studies the main factors affecting the quality results, such as data, technology and processes. With analyses the process quality control content and methods applicable to the monitoring data production, it determines the quality control of process nodes, process technology and process technology to ensure the quality of the final results.

\section{PRINCIPLES OF PROCESS QUALITY CONTROL}

\subsection{Influencing Factors of Process Quality}

The consistency and stability of data quality are controlled by the production process. In the production process stage, data is dynamic data that is changing, which can reflect the details of actual production, trace the causes of problems, find abnormal manufacturing performance, and effectively prevent the production of defective products. The factors affecting process quality can be divided into the following aspects: operators, equipment, data sources, content methods.

2.1.1 Operators: The impact of production workers on data quality is as follows: uniformity in the understanding of technical regulations, standardization of operating procedures, and consistency in handling technical issues.

2.1.2 Equipment: The impact of the equipment used on the data quality is as follows: whether the hardware equipment meets the production accuracy requirements, whether the selfdeveloped software has been verified and confirmed, etc.

2.1.3 Data Sources: The impact of data sources on data quality is manifested as: data source reliability, timeliness, accuracy, etc.

2.1.4 Content Methods: The content method's impact on data quality is manifested as: the compliance of the collection content method with the technical design requirements, the integrity of the collection data, and the correctness of the collection method.

\subsection{Process Quality Control Method}

The main methods of process quality control are:

- First Article Inspection: Combination of self-inspection, mutual inspection and special inspection;

- Process control combined with random inspection and patrol inspection;

- Multi-process Centralized Inspection;

\footnotetext{
* Corresponding author
} 
- Inspect Step by Step;

- Inspection after Product Completion;

- Combination of Sampling and Full Inspection.

\section{PROCESS QUALITY CONTROL DESIGN}

\subsection{Establishment of Quality Control Key Points}

On the whole, monitoring quality control key points include the operation of the quality management system, the consistency of the stage results with the production technology requirements, the conformity of the production processes (such as data sources, internal editing, field verification) and technical means, etc.

From the perspective of the completion of each process, including image correction, image interpretation and classification correctness, completeness of content index collection, and accuracy compliance, etc. As shown in Figure 1.

\section{Quality Control Key Point}

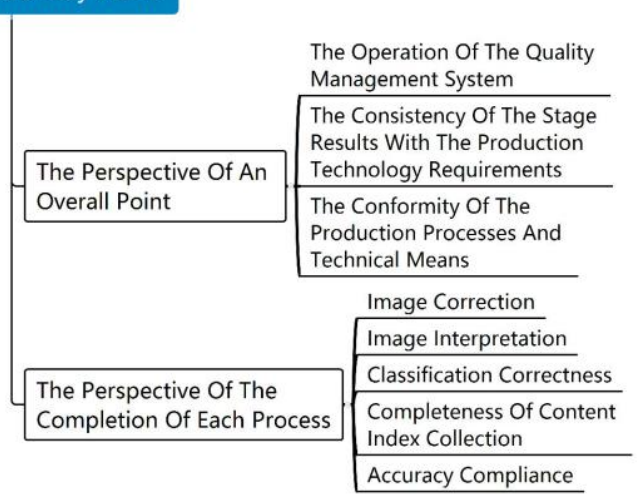

Figure 1. Quality control key points.

\subsection{Content of Process Quality Control}

The main content of process quality control is divided into two parts, one is the inspection of quality management, and the other is the inspection of quality control in the production process. As shown in Figure 2.

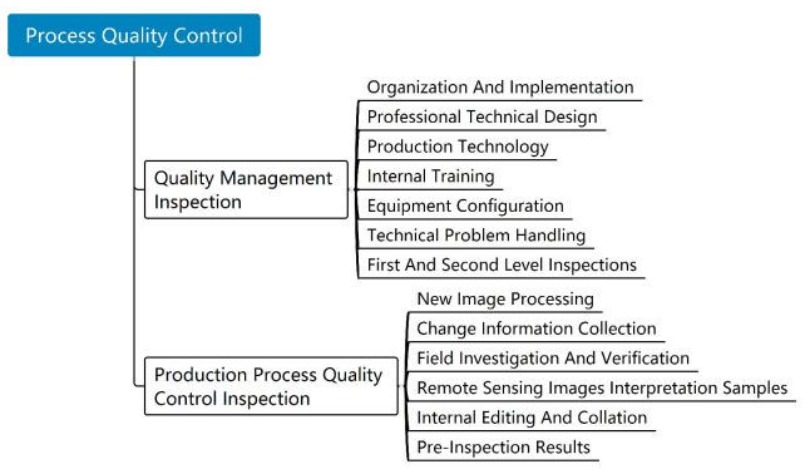

Figure 2. Content of process quality control.
3.2.1 Main Content of Quality Management Inspection: The main content of the quality management inspection includes organization and implementation, professional technical design, production technology, internal training, equipment configuration, technical problem handling, and first and second level inspections.

3.2.2 Main Content Of Production Process Quality Control Inspection: The main content of the quality control inspection of the production process is divided into 6 main stages according to the characteristics of the project results and the production technology route, which are the key nodes of process quality control, including new image processing, change information collection, field investigation and verification, and remote sensing images interpretation samples, internal editing and collation, and pre-inspection results. Table 1 uses change information collection as an example to illustrate the specific content of process quality inspection.

\begin{tabular}{|c|c|}
\hline $\begin{array}{c}\text { Inspection } \\
\text { of Key Node }\end{array}$ & Check Content \\
\hline \multicolumn{2}{|c|}{ (1). Data Source Situation } \\
\hline \multicolumn{2}{|c|}{ a. Consistency with Background Data } \\
\hline $\begin{array}{l}\text { b. Image } \\
\text { Utilization } \\
\text { Analysis }\end{array}$ & $\begin{array}{l}\text { Overall Coverage } \\
\text { Whether to cover completely without } \\
\text { missing } \\
\text { Whether the image of the absolute } \\
\text { vulnerability area is supplemented as } \\
\text { required } \\
\text { Quality Situation } \\
\text { Whether the image has a large area } \\
\text { of cloud and snow occlusion } \\
\text { Whether the image resolution meets } \\
\text { the requirements } \\
\text { Whether the image time phase meets } \\
\text { the requirements }\end{array}$ \\
\hline $\begin{array}{l}\text { c. Analysis } \\
\text { of The Use } \\
\text { of Thematic } \\
\text { Data }\end{array}$ & $\begin{array}{l}\text { - Current status of thematic data sources } \\
\text { - The authority of thematic data sources } \\
\text { - The analysis and integration of thematic } \\
\text { data }\end{array}$ \\
\hline
\end{tabular}

(2). Land Cover Classification Data

\begin{tabular}{|c|c|}
\hline $\begin{array}{l}\text { a. Missing } \\
\text { Area } \\
\text { Identification }\end{array}$ & $\begin{array}{l}\text { Focus on checking the completeness of } \\
\text { the change pattern extraction } \\
\text { In particular, the extraction of new } \\
\text { housing constructions, the rationality } \\
\text { of comprehensive extraction of } \\
\text { housing construction areas, etc. } \\
\text { The support of vegetation change } \\
\text { classification and image texture and } \\
\text { tone, and reasonable differentiation } \\
\text { of vegetation changes, such as } \\
\text { natural growth changes and artificial } \\
\text { farming changes between planting } \\
\text { land, forest and grass cover, etc. } \\
\text { In particular, distinguish seasonal } \\
\text { changes in image features to } \\
\text { reasonably extract change patterns } \\
\text { The binding relationship between land } \\
\text { cover and geographical conditions }\end{array}$ \\
\hline b. Change & b-1. Whether the regional change patterns of \\
\hline
\end{tabular}




\begin{tabular}{|c|c|}
\hline $\begin{array}{l}\text { Information } \\
\text { Collection }\end{array}$ & $\begin{array}{l}\text { different monitoring types meet the } \\
\text { collection requirements } \\
\text { Consistency of the map boundary and } \\
\text { image segmentation, and whether the } \\
\text { position accuracy meets the specified } \\
\text { requirements } \\
\text { - Change pattern collection accuracy, } \\
\text { change information collection index } \\
\text { grasp } \\
\text { - Consistency of the extraction } \\
\text { principles of land cover changes, } \\
\text { especially the level of detail of the } \\
\text { classification maps with the same } \\
\text { image texture and tone } \\
\text { The conformity of changing pattern } \\
\text { classification with image texture and } \\
\text { tone (internal interpretation) } \\
\text { The correctness of the change type, such } \\
\text { as: } \\
\text { - Scalable: Keep the classification } \\
\text { consistent with the background data } \\
\text { - Whether the change type is } \\
\text { consistent with the actual situation } \\
\text { and the assignment principle } \\
\text { - Confusion between scaling changes } \\
\text { and nascent changes } \\
\text { b-2. Whether the urban area conducts } \\
\text { change collection in accordance with } \\
\text { regulations } \\
\text { Change map spot collection accuracy } \\
\text { and change information collection index } \\
\text { grasp, such as: } \\
\text { - Classification requirements: urban } \\
\text { areas need to be subdivided into } \\
\text { three categories }\end{array}$ \\
\hline $\begin{array}{l}\text { c. Dealing } \\
\text { with The } \\
\text { Relationship } \\
\text { Between } \\
\text { Related } \\
\text { Spots }\end{array}$ & $\begin{array}{l}\text { Topological consistency between } \\
\text { updated data and original elements } \\
\text { There are very small faces and } \\
\text { narrow faces } \\
\text { - Intersecting faces, overlapping faces, } \\
\text { etc. }\end{array}$ \\
\hline $\begin{array}{l}\text { d. Content } \\
\text { Identification } \\
\text { of Field } \\
\text { Inspection } \\
\end{array}$ & $\begin{array}{l}\text { Whether the doubtful spots and the } \\
\text { attributes of new elements that need } \\
\text { field verification are clearly marked }\end{array}$ \\
\hline \multicolumn{2}{|c|}{ (3). Geographical National Condition Data } \\
\hline $\begin{array}{l}\text { a. Missing } \\
\text { Area } \\
\text { Identification }\end{array}$ & $\begin{array}{l}\text { Completeness of new feature extraction } \\
\text { - Completeness of extraction of change } \\
\text { elements } \\
\text { Whether the relationship between new } \\
\text { and changed elements and related } \\
\text { elements has been extracted completely } \\
\text { - Whether the newly built and diverted } \\
\text { roads and ponds are fully extracted } \\
\text { - Sufficient extraction of changes, new } \\
\text { urban streets and pavements and } \\
\text { related elements } \\
\text { After updating the location of the } \\
\text { water system elements, pay attention } \\
\text { to whether there are unupdated } \\
\text { climbing slopes, redundant structural }\end{array}$ \\
\hline
\end{tabular}

\begin{tabular}{|c|c|}
\hline & lines and river structural lines \\
\hline $\begin{array}{l}\text { b. Change } \\
\text { Information } \\
\text { Collection }\end{array}$ & 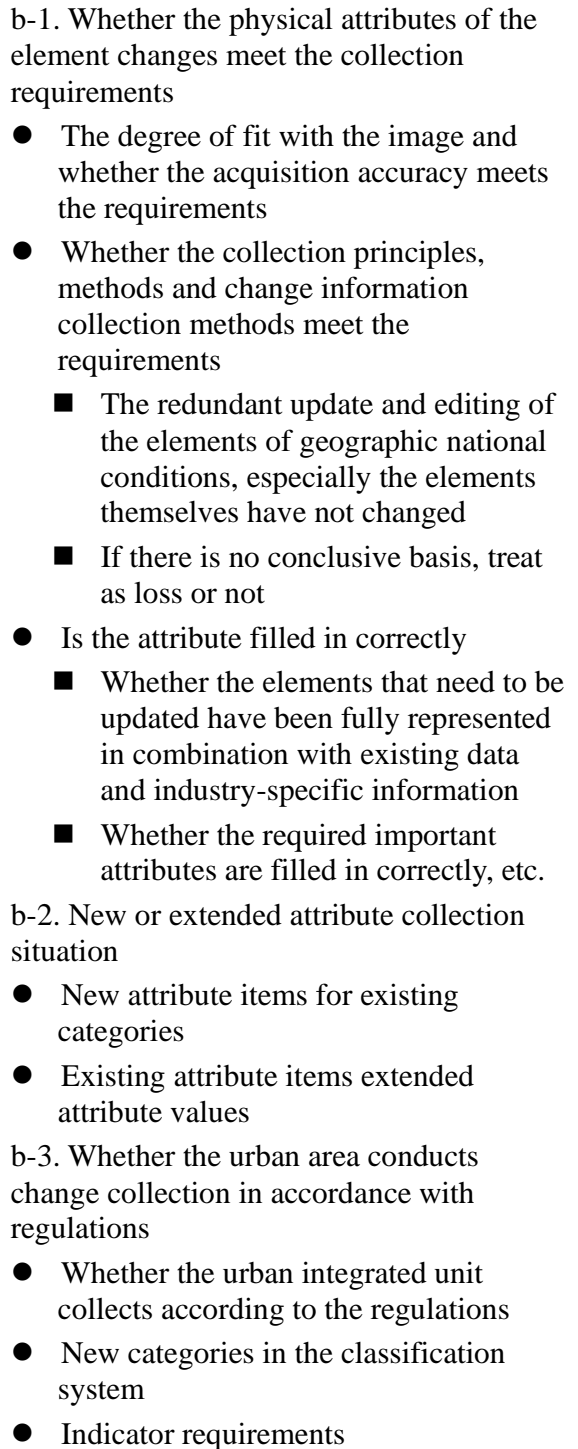 \\
\hline $\begin{array}{l}\text { c. } \\
\text { Connection } \\
\text { with Original } \\
\text { Elements }\end{array}$ & $\begin{array}{l}\text { Topological consistency between } \\
\text { updated data and original elements } \\
\text { - Road intersection is not interrupted } \\
\text { - Pseudo nodes exist in solid } \\
\text { intersection }\end{array}$ \\
\hline $\begin{array}{l}\text { d. Content } \\
\text { Identification } \\
\text { of Field } \\
\text { Inspection }\end{array}$ & $\begin{array}{l}\text { Whether the doubtful spots and the } \\
\text { attributes of new elements that need } \\
\text { field verification are clearly marked }\end{array}$ \\
\hline
\end{tabular}

Table 1. Specific content of process quality inspection (take change information collection as an example). 


\section{PROCESS QUALITY ANALYSIS}

\subsection{Process Quality Management}

4.1.1 Lax Organizational Management Awareness: With the transition by the time of the monitoring period, problems such as unsound organizational structures, limited institutional role play, slack awareness of quality management, and inadequate implementation of management efforts occurred. The quality requirements that the operating units should meet were not timely make planning, guidance and supervision.

4.1.2 Process Quality Control Is Not Fully Implemented: The project undertaker has not carried out or completed the process quality control, and cannot guarantee that all procedures and links are in a quality control state. The problems reflected from the data source factors, technical factors and management factors are specifically manifested in the insufficient quality control of the first drawing, the inadequate quality control of the process, and the ineffective control of the original data.

\subsection{Production Quality Control}

4.2.1 The Image Source Is Not Enough to Guarantee the Monitoring Needs: In some areas, there are still incomplete image coverage, image time phases that do not meet the requirements, and overall deviation of image correction, which directly affects the ultimate reliability of the quality of monitoring results. The first is that the time-phase fluctuation range of the image used is large; the second is that there are image coverage loopholes; the third is that the uniformly issued background data orthoimage is not used for correction processing. There is a systematic deviation of 4-6 meters in the fitting error.

4.2.2 Lack of Training On Monitoring Content For Operators: On the one hand, some operators are unfamiliar with the monitoring results in the use of source data, handling of technical issues, interpretation of change information, etc.; on the other hand, some operating units and personnel have not participated in census production, lack of systematic business training, these factors directly affect the quality of monitoring results.

4.2.3 Technical Verification Is Not in Place: It is difficult to grasp the data quality of change information collection, change area identification, collection requirements and recording methods, and the logic between features. Quality issues such as misjudgement of change information, missing or false update of change information and improper handling of relationships between features are all related to technical verification. During the inspection, it was found that insufficient attention was paid to the design verification work. The specific manifestations were the lack of or incomplete verification of the first article design, the incomplete inspection of the first article results, the insufficient inspection problems in the form of the verification workflow, and the remaining unsolved problems or no clear problems.
4.2.4 The Function Of Independently Developed Software Has Not Been Tested: In order to improve production efficiency, most units independently develop relevant tool software, but when using these software in production, the software functions and performance are not tested and verified. Especially when there are general attribute item assignments such as change information and default value filling in the monitoring results, there are obvious errors that have not been completely resolved in some key links. In order to avoid rework and to ensure the reliability, stability and accuracy of the software, it should be legally tested and approved by the relevant department before being put into use on a large scale.

\subsection{Achievement Quality}

4.3.1 Inaccurate Recognition of The Change Area: Extracting the change area of the seasonally changing feature category, for example, the water surface coverage is very unstable due to the difference of the images time phase. Extracting as a change area will cause differences in the changes of several feature categories in the later results, and there will be a pseudo-update phenomenon. As shown in Figure 3.

Inaccurate understanding of the changes in land types, such as the partial mismatch, and the wrong projection error as the change of information, resulting in more acquisition of the actual unchanged information.
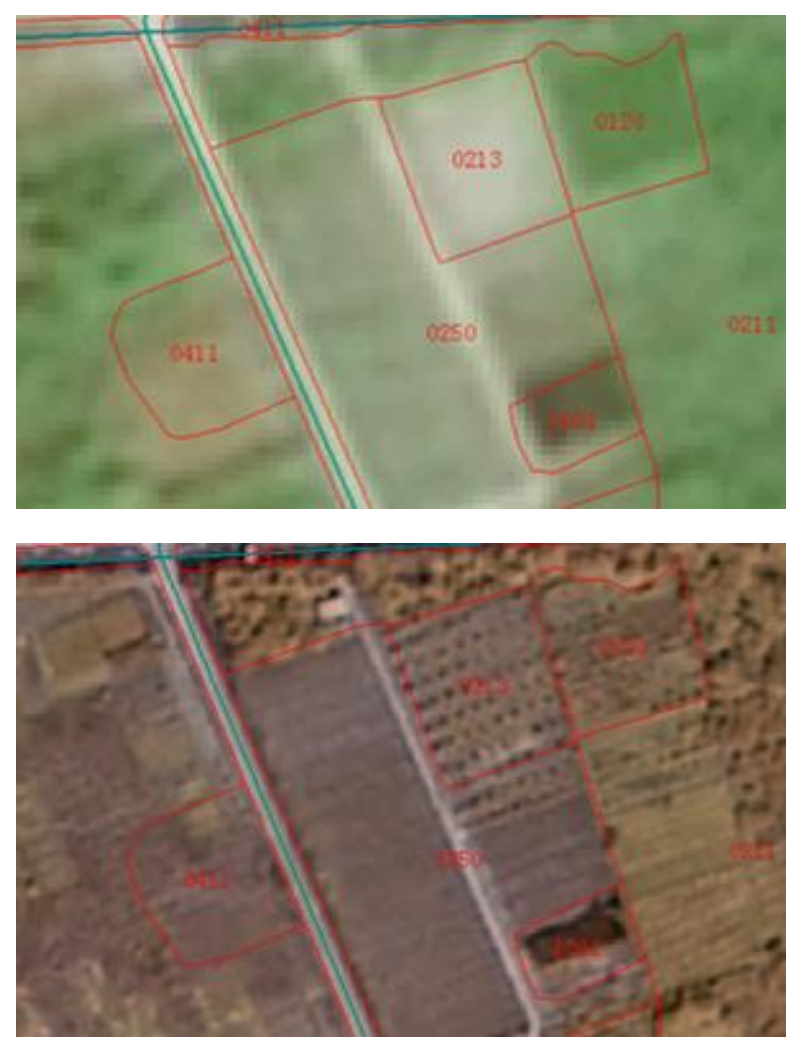

Figure 3. Pseudo update phenomenon due to resolution and time phase changes of two-phase image. 
4.3.2 Errors and Omissions of The Changes and The Position Accuracy Exceeds the Limit: There are some update errors or lack of basis for the update in the internal collection. The specific manifestations are: dry land, nursery, arbourirrigated orchard, etc. It appears as inconsistent with the image interpretation, doubtful or difficult to interpret. The map is not marked with verification markings; classification errors caused by unreasonable segmentation and merging of patterns such as housing construction areas and hardened ground surfaces.

For example, the classification of change patterns caused by excessively large collections is missing; the accuracy of updating the positions of the spots exceeds the limit, such as the classification code is updated when collecting expansion or new-type change patterns, but without modifying the border of the pattern.

4.3.3 Incomplete Collection of Change Attribute Information: Missing collection of national conditions elements, or missing attribute values such as missing attribute items for newly added roads; missing collection of overpasses in urban areas; incomplete collection of urban roads and national highways; unprocessed or unreasonable overlapping sections, etc. As shown in Figure 4.
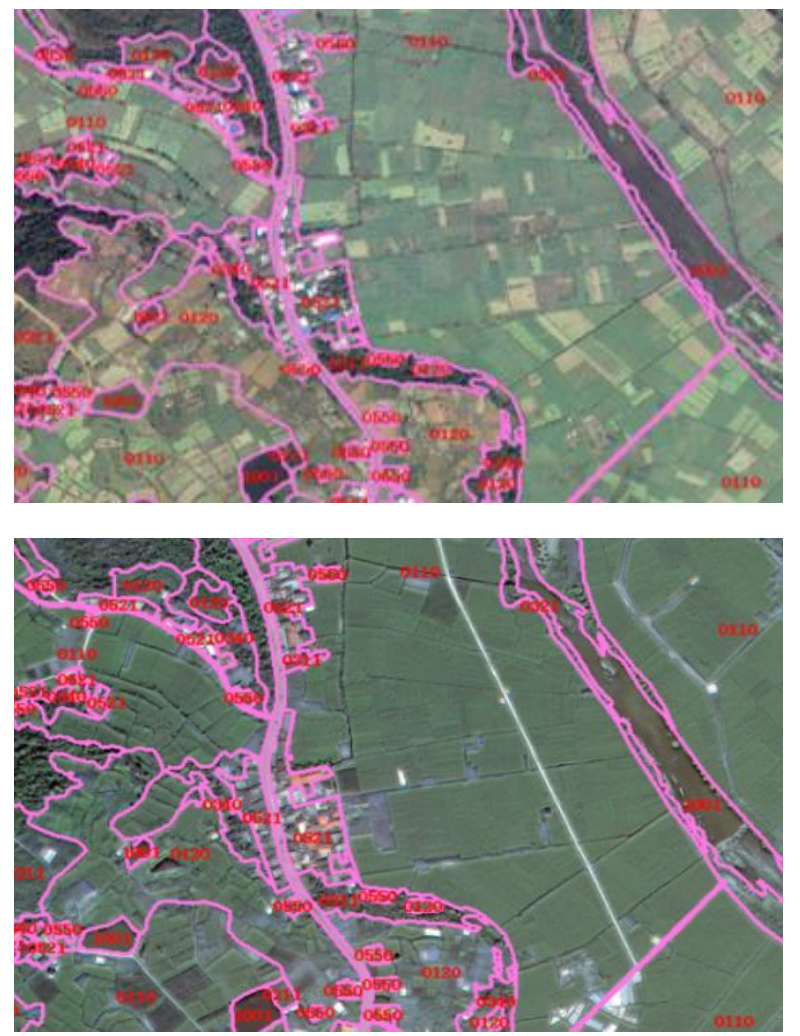

Figure 4. Missing to collect a new road of two-phase image.
4.3.4 The Logical Relationship Between Features Is Unreasonable: The constraint relationship between the unprocessed or improperly processed elements during the update collection, and between the land cover classification spots and the corresponding elements. For example, if the national conditions are updated, the inconsistency between the appearance of the water body (surface) layer and the collection of the covering water surface is not updated; for the road layer data, there are unreasonable indications such as ramps and roads or ancillary connections; The logic of the relationship of the road (line) and the overburden pavement appears as line is wrong.

4.3.5 The Value Of The Element Attribute Item Is Wrong: The value of the attribute item of the new or changed information is incorrectly assigned or the value is abnormal, specifically as the "ChangeType" attribute item; the value of the attribute item of "Up and Down" or "Single Bidirectional/Single Double Line" is assigned logical contradiction; the value of the attribute item has been updated, but not modified as required in the "update field (ChangeAtt)" and other items.

\section{CONCLUSIONS}

According to the technical characteristics and operational characteristics of geographic national conditions monitoring, this paper has determined the key points and content of process quality control. The research results will be used as technical regulations in geographic national conditions monitoring documents from 2016 to 2020, and have been guided and applied to nearly 10 batches of the supervision work provided an effective guarantee to ensure the quality of the final results.

\section{REFERENCES}

Gao, W.C., Zhao, H.T., Mao, W.J., Yin, S., Tian, Z.B., 2020: Construction research and application of fundamental geographic national condition monitoring quality control system. International Archives of the Photogrammetry, Remote Sensing and Spatial Information Sciences - ISPRS Archives. doi.org/ 10.5194/isprs-archives-XLIII-B3-2020-1327-2020.

Li, D., Ma, J., Shao, Z., 2018: Innovation in the census and monitoring of geographical national conditions. Wuhan Daxue Xuebao (Xinxi Kexue Ban)/Geomatics and Information Science of Wuhan University, 43(1), 1-9. doi.org/ 10.13203/j.whugis 20170356.

Li, D., Sui, H., Shan, J., 2012: Discussion on key technologies of geographic national conditions monitoring. Wuhan Daxue Xuebao (Xinxi Kexue Ban)/Geomatics and Information Science of Wuhan University, 37(5), 505-512. doi.org/10.1007/s11783011-0280-z.

Zhang, J., Li, W., Zhai, L., 2013: Understanding geographical conditions monitoring: a perspective from china. International Journal of Digital Earth. doi.org/10.1080/17538947.2013. 846418.

Zhang, J., Zhai, L., 2016: Thoughts on the normalized monitoring of geographical national conditions. Geospatial Information, 14(4), 1-3. doi.org/10.3969/j.issn.1672-4623.2016. 04.001 . 